\title{
SCIENTIFIC AND METHODOLOGICAL APPROACH TO A COMPREHENSIVE ASSESSMENT OF THE ECONOMIC STABILITY OF A TELECOMMUNICATIONS COMPANY
}

\author{
Svitlana Birbirenko', Galina Tolkachova²
}

\begin{abstract}
The COVID-19 pandemic has ultimately changed the course of global economic functions, including the Ukrainian ones. The consequences caused by the pandemic significantly affected companies' economic sustainability and reflected the urgent need to assess economic sustainability in order to determine its level and further develop theoretical and methodological aspects of Strategic Enterprise Management. This article is aimed at developing a scientific and methodological approach to comprehensively assess the economic stability of a telecommunications company that operates under modern market conditions. Methods. A study was conducted within the scope of existing techniques used to assess economic stability and, thus, the lack of generally accepted assessment methods was observed. A set of indicators to assess the economic stability of the telecommunications company was formed through financial analysis, taking into account the industry practices of communications service provider's functioning. Comprehensive assessment of the economic stability of telecommunications companies was carried out using a statistical data analysis technique - regression analysis. 2016-2020 financial reports and statistical data provided by examined communications service providers from the State Statistics Service of Ukraine and the National Commission of Ukraine for the State Regulation of Communications and Informatization were used as outcoming data. Study results. As part of the study, the existing assessment methods were analyzed, which made it possible to organize, systematize, and identify their advantages and disadvantages. A set of indicators to assess economic stability of a telecommunications company was formed, indicating the selection criteria and identifying dependence on the presence of a communications service provider at a certain stage of its business development. A scientific and methodological approach to a comprehensive assessment of the economic stability of telecommunications companies taking into account their industry characteristics has been developed. Conclusions. The created scientific and methodological approach to assess economic stability of the telecommunications company comprehensively makes it possible to determine the level of economic stability depending on the stage of business development of a company. The assessment performed is a key factor that must be taken into account when developing strategic management of a company that operates in the context of market transformations.
\end{abstract}

Key words: economic stability, integrated assessment, balanced indicators, strategic management, telecommunications company.

JEL Classification: D81, L25, L96, O40, 012

\section{Introduction}

Current instability of the market economy is aggravated by the crisis triggered by the spread of COVID-19 caused by SARS-CoV-2. Therefore, in order to implement economic activities by any company (particularly a telecommunications company), it is necessary to have a quick and reasonable response to business changes that may violate its stable and profitable existence. The maximum profit orientation is definitely no longer a key driver since development ensuring economic stability should be carried out. Generally speaking, this applies both to social development and national economy's development, its individual sectors, and particularly a telecommunication sector which, along with other sectors, forms the development potential of the state.

\footnotetext{
Corresponding author:

${ }^{1}$ State University of Intellectual Technologies and Communications, Ukraine.

E-mail: sveta_novickaya@ukr.net

ORCID: https://orcid.org/0000-0003-2355-4949

ResearcherID: AAR-3305-2021

${ }^{2}$ State University of Intellectual Technologies and Communications, Ukraine.

E-mail: dront2009@ukr.net

ORCID: https://orcid.org/0000-0002-4374-5737
} 
Communications, informatization, and telecommunications sector in particular, play an important part in shaping national economy since they integrate the results of a large number of related sectors of the national economy and are indicators of the scientific and technological development and potential for any country. Thus, the level of economic stability of telecommunications companies basically determines the economic development of a state, its information and communications potential, scientific and technological progress, and competitiveness in domestic and foreign markets.

Therefore, in the context of the coronavirus crisis, when the Ukrainian economy suffered significant losses and, nevertheless, was integrated into the global economic space, questions arise on the development of new concepts of strategic management, methods and approaches to the economic stability of telecommunications companies. A comprehensive assessment is determined, which is a set of actions that can be used to identify the dynamics of indicators and trends in their changes over time, on the basis of which the effectiveness of a company has been studied.

This study aims to develop a scientific and methodological approach to assess the economic stability of a telecommunications company comprehensively. Comprehensive assessment was carried out using regression modeling, a statistical data analysis technique. Three leading Ukrainian telecommunications companies were selected to conduct the analysis: Kyivstar PJSC, VF Ukraine PrJSC and Ukrtelecom PJSC. 2016-2020 financial reports and statistical data provided by examined communications service providers from the State Statistics Service of Ukraine and the National Commission of Ukraine for the State Regulation of Communications and Informatization were used as outcoming data.

\section{Analysis of the existing assessment methods}

The study of the existing methods to assess economic stability of a company proved the lack of a unified approach to the assessment procedure.

Pursuant to (Afonichkin, Zhurova, 2015; Revenko, Dyba, 2014) there are three methods to arrange an integral indicator of economic stability of a company, which are most often used during the assessment:

1) Sum method (additive method). The integral indicator of economic stability is defined by calculating the weighted average assessment of components using weight coefficients:

$$
P_{S}=\sum_{i=1}^{n} q_{i} \times P_{i},
$$

where $P_{s}$ is an integral indicator of economic stability of a company; $P_{i}$ is a level of economic stability of $i$-th component of economic stability of a company; $q_{i}$ is weight ratio of $i$-th component of economic stability of a company; $n$ is the number of components in economic stability of a company.

2) Functional method. The overall level of economic stability of a company is determined through a set of variables:

$$
P_{f}=a_{1} f\left(x_{1}\right)+a_{2} f\left(x_{2}\right)+\ldots+a_{m} f\left(x_{m}\right),
$$

where Pf is a general level of economic stability of a company; $a_{1}, a_{2} \ldots$ am are weight coefficients of each indicator of economic stability of a company; $x_{1}, x_{2} \ldots$ $x_{m}$ are main performance indicators of a company; $f\left(x_{1}\right)$, $f\left(x_{2}\right) \ldots f\left(x_{m}\right)$ are local dependence functions of the general level of economic stability of a company on the corresponding indicators of its activity; $i$ is the number of performance indicators of a company.

3) Rating method. This method is applied when rating assessment of the integral indicator and comparing company's indicators with industry average values. The functional components of the economic stability of a company are calculated using the dynamic rating method:

$$
P_{p}=\sum_{i=1}^{z} \frac{1}{Z_{i} \times N_{i}} \times K_{i},
$$

where $P_{p}$ is an aggregated factor of the company's economic stability separate component;

$Z_{i}$ is the number of indicators used to assess the level of economic stability for a separate component;

$N_{i}$ is a regulation value for $i$-th coefficient;

$K_{i}-i$-th coefficient.

The obtained aggregated factors for each component of economic stability are added in order to determine the overall level of economic stability based on the reference value, which is the sum of units of the number of complex indicators.

Many scientific papers are devoted to the problems of substantiating methodological tools and algorithms to assess the economic stability of a company. Thus, Brahinets A.M. considers indicators of economic stability components of the financial solvency of a company (Brahinets, 2009). Ulianchenko O.V. considers profitability to be a generalizing indicator of the economic stability of a company (Ulianchenko, 2006). Tridid O.M. identifies 16 stability indexes, including the degree of financial leverage, leverage ratio, return on equity, equity maneuverability, etc. (Tridid, 2002).

Foreign scientists also pay a lot of attention to the study of the essence and assessment of economic stability. To be more specific, M. Siegrist et al. believe that the economic justification for stability can be based on reducing the costs, increasing the revenues, and managing the risks and intangible assets (Siegrist, 2019). T. Fetzer et al. systematically evaluated the rate of occurrence and causal determinants of economic anxiety as a prototype of economic stability when the coronavirus pandemic was just unfolding, when the 
extent of its economic impact was uncertain. The authors also focus on the perception of pandemic risk factors that form the so-called "economic concerns" (Fetzer, 2020). German scientist Klaus-Jürgen Gern and his colleague draw attention to the indirect economic consequences that result from measures to direct the pandemic or changes in consumer behavior (Gern, 2020). F. Carlson-Schlesak et al. hold to the opinion that to get an idea of the recovery path, companies' CEOs should carefully consider market signals between different asset classes, develop a sustainability model, as well as look beyond the markets at recession and recovery models, and study the history of pandemics and collapses (Carlsson-Szlezak, Reeves \& Swartz, 2020).

A common and well-known method to assess the economic stability of a company is based on the principles of evaluating financial results, which include profit, profitability, cost, solvency, etc. Various options combining indicators that act as an indicator for different operating conditions and industry affiliation of companies have also been used. The total number of financial analysis indicators used in modern practice exceeds 150.

Based on the study and analysis of scientific achievements to determine the level of economic stability, we have identified the following groupings of methods to assess the economic stability of a company: 1) assessment methods based on the analysis of the financial condition of a company and calculations to determine the probabilities of its bankruptcy;

2) assessment methods based on calculations of a summarizing indicator calculated using the principles of a systemic approach (arithmetic mean, geometric mean, rating assessment indicators, etc.) to determine the level of economic stability. This generalizing indicator is based on the assessment of individual structural elements (components) that reflect certain areas of activity of a company (Burlaka, 2014; Hordiienko, 2011; Kobets, 2015);

3) assessment methods using relative indicators and weight coefficients which are calculated on the basis of expert methods (Yurchenko, 2018; Kravchenko, 2016; Voronkova, 2008);

4) methods to assess the comprehensive level of economic stability of a company, based on the use of quantitative and qualitative methods of the analysis (Kobets, 2015; Ishchenko, 2011).

The most common methods from the general set of methods that have been analyzed are those that were calculated using an integral indicator, which fundamentally is a formalized method that combines arrays of analytical characteristics.

Based on the analysis of the above methods to assess the economic stability of a company, we can summarize that:

1) the economic stability of a company is characterized by complexity which dictates the need to take the most important structural and functional components into account;

2) the vast majority of the methods examined make it possible to diagnose the economic stability of a company, however, without specifying recommendations how to develop the measures to control the process of formation, coverage and improvement of the level of the economic stability of business entities that carry out their activities in crisis conditions (which are now quarantine restrictions caused by the spread of COVID-19);

3) most methods are based on the use of a large number of identical indicators or similar indicators;

4) the recommended criteria indicators do not look to the specific features inherent in individual industries;

5) the methods proposed are practically devoid of taking into account disturbing influences from the external environment, especially when they transform frequently.

We believe that scientific and methodological approaches to integrally assess the economic stability of the telecommunications company should be formed on the basis of pre-defined priorities when studying the entity, namely, when analyzing operational performance indicators (Otchenashenko, 2011).

While forming a reasonable conclusion about the development trends of a certain economic category, some difficulties emerge when processing a large amount of information that is crucial study interrelated indicators individually. Consequently, the modern system analyzing theoretical and practical part of economic categories and indicators provides for the use of a formalized method to combine large arrays of analytical indicators that can be synthetic, generalizing, aggregated or integral forms. Therefore, determining the level of economic stability of the telecommunications company is mostly widespread when quantitatively assessing the key indicator of company's functioning based on the definition of a generalizing assessment of economic stability.

Undertaking integral assessment of economic stability, it is possible to assess not only its common level based on the use of the developed scale, but also to assess individual structural elements of stability. This method is characterized by the use of existing methods when assessing a certain set of indicators. Updating and increasing the capabilities of a traditional analysis take place, as well as comparing the obtained indicators with various standards, objectives, criteria inherent in the field of communications and informatization. The calculated results of integral assessment can be used while evaluating the effectiveness of management decisions, their justification for further implementation at the necessary hierarchical levels of economic management.

Thus, the obtained conclusions referring to the forms and content of indicators assessing the economic 
stability of a company indicate that modern practice has no single generally accepted assessment method. Almost every researcher who studies the methods to assess economic stability recommends applying his or her version when formalizing the indicator, providing certain arguments when practically justifying its content and possibilities of applying it.

The above considerations reveal that a scientific and methodological approach to assess the economic stability of a company (on the example of telecommunications companies) based on a comprehensive coverage of all the main functioning aspects in the modern market space are crucial.

\section{Formation of a set of indicators to assess the economic stability of a telecommunications company}

The process to study the activity of a company, namely, the formation of the level of its economic stability is characterized by the problem of substantiating the criteria for selecting indicators that are components of a balanced assessment array. These criteria should include the industry practices and specifics of the company analyzed, taking into account the conditions of a certain stage of the life cycle.

In our opinion, the formation of a set of indicators to evaluate the performance of the telecommunications company justifying the sufficiency of its economic stability should be based on the use of such selection criteria:

- formulation of all processes that will determine the indicators and their permissible application;

- coherence of indicators with the transformation of the external environment and its strategy;

- selection of indicators based on the stages of business development;

- predominance of the quantitative indicators over the qualitative ones;

- prevention of indicator multicollinearity;

- complete reflection and logical linking of tasks performed by various structural divisions and the company particularly;

- the ability to integrate into the generally accepted document management scheme in the company.

Certain criteria to select the indicators, taking into account their characteristics, are substantial when organizing a set of balanced indicators to assess the economic stability of a telecommunications company. The set of balanced indicators is based on four components that make it possible to achieve a balance between long-term and short-term goals, between desired results and factors, as well as between hard objective criteria and soft subjective indicators. Finance, subscribers, internal business processes, as well as staff training and development, are the components for a telecommunications company.
We believe that the indicators of the financial component of the formation of a set of balanced indicators are characterized by a key role and their selection should be carried out taking into account the stage of business development of a telecommunications company.

We established that the initial stage when setting up a telecommunications company, accelerated growth, sustainable development and stagnation are the stages of business development.

The initial stage of the telecommunications company formation is characterized by its gradual penetration into the communications and informatization market. Nevertheless, its technical and economic setting up and assets accumulate intensively. A company needs high potential, maximum mobilization of financial resources to develop and promote its services to the market, as well as sufficient investment in fixed assets and infrastructure, in order to improve the quality of services provided, and introduce the new ones. That is why it is urgent to expand the subscriber base. The amount of investment in development often exceeds the income of a company. At this stage of telecommunications company business development, liquidity, financial stability, and property status indicators require careful analysis. Special attention to the financial leverage ratio (if the telecommunications company shares borrowed funds) should be payed, which makes it possible to control dependence on external sources, increase the probability of financial risks and comply with guarantees to repay the obligations by the company. Furthermore, at this stage of development, telecommunications companies should carefully analyze the indicators for assessing their position in the stock market, monitor the relation between the dividend policy and the corporation law market rate. The completion of the initial stage of development by the telecommunications company should be characterized by a steady growth in liquidity, financial stability, business activity and profitability ratio.

Characteristic features of a telecommunications company's entry and long-term period at the stage of accelerated growth imply the increase in the volume of services provided, recognition by subscribers and counterparties. The process of providing services at this stage is determined by intensive modernization, and the quality of the services provided significantly improves. The telecommunications company is in dire need of investment and reinvestment, and a significant increase of its potential with an increase in demand for communication services becomes predictable. In addition to keeping it, a significant expansion in the communications and informatization market section occurs. This stage of business development is determined by the stability of liquidity, financial stability, and property status indicators. When these indicators are destabilized, we can conclude that the 
company has not achieved the proper level of economic stability, which encourages a review of key aspects of strategic management and their adaptation to potential opportunities. It becomes necessary to focus on operating profit and gross profit, the growth rate of which should be satisfactory. An increase in economic stability reflects sufficient investment in fixed assets, accompanied by an increase in the income received. The performance criterion that helps to remain on the securities market should also have a positive dynamics. As a result of the telecommunications company's planning to further attract financial resources through an additional issue, it is necessary to develop a dividend policy, the main purpose of which will be to increase the corporation law market rate.

The stage of telecommunications company's sustainable development should be characterized by achieving stability in terms of profitability when providing services and striving for consistently high return on equity. This stage is characterized by an increase in return on investment and an increase in return on invested capital. A sufficient level of economic stability at this stage is confirmed by the stability of business activity, property status and profitability indicators. If a decrease in these indicators is observed, it is urgently advisable to increase the effectiveness of strategic management of economic stability in order to avoid falling into the stage of stagnation.

The stage of stagnation of the telecommunications company is characterized by value aging (production primarily), a decrease in the quality and competitiveness of services. This stage is characterized by destabilization of all financial indicators. Indicators of liquidity, profitability, property status in this case, as well as indicators that determine the position of a company in the stock market are the key indicators. Therefore, it is possible to determine the feasibility of continuing activities at the rate of the developed strategic management. This stage is caused by a recession, which most often leads to bankruptcy, and that requires emergency implementation of anti-crisis management.

Thus, the main indicators for each component of the combination of balanced indicators were formed and justified, which made it possible to analyze the state of economic stability of telecommunications companies in such components as finance, subscribers, internal business processes, as well as training and developing personnel.

\section{Scientific and methodological approach to assess economic stability}

The above information specifies that to assess the economic stability of a telecommunications company, a set of balanced indicators is applied; it combines four most important components of the company's functioning: finance, work with subscribers, internal business processes and training, and development of personnel. The final establishment of the level of economic stability of the analyzed telecommunications companies requires the implementation of analytical studies of the indicators of the specified set in accordance with certain stages.

The first stage of the scientific and methodological approach includes forming a set of balanced indicators. In order to assess the financial and economic condition (financial component of the set of balanced indicators) of three leading Ukrainian telecommunications companies (Ukrtelecom PJSC, Kyivstar PJSC, VF Ukraine PJSC) for five years (2016-2020), the analysis of liquidity, efficiency (profitability) of activities, financial stability (independence), business activity and property status, namely, the key indicators of the financial components, is carried out. Individual key indicators of the assessment $\left(\mathrm{x}_{\mu}{ }^{\mathrm{i}}, \mu=\overline{1, n}\right)$ are calculated for each integral indicator (ICBSC, $i=\overline{1,4}$ ) of the separate component of the balanced scorecard. Regression modeling is used to calculate integral indicators for each component of the balanced scorecard.

The second stage when assessing the economic stability of the telecommunications company is the calculation of effective indicators for each component of the balanced scorecard and their interpretation.

Based on the principles of regression modeling, linear regression equations were compiled and presented in Table 1 for each effective indicator.

The next stage includes calculating the overall integral indicator of economic stability (IOES) of the telecommunications company and establishing its compliance (depending on the stage of business development of the telecommunications company) with a certain level of economic stability. Calculation of the overall integral indicator of economic stability (IOES) is carried out by evaluating four components, taking into account their weight: financial (IfcSC); subscriber (IsubBSC); internal business processes (IibpBSC); personnel training and development (IptdBSC).

Overall integral indicator to assess economic stability (IOES) is calculated as follows:

$$
I_{O E S}=\sum_{i=1}^{4} k^{i} \times I_{C B S C}^{i} \text {. }
$$

where $k^{i}$ is weight of $i$-th integral indicator of each individual component of the balanced scorecard of economic stability of a company;

IiCBSC is an integral indicator of each individual component of the balanced scorecard of economic stability of a company.

For this purpose, $k^{i}$ is determined by an expert method and is reduced to:

$$
\sum_{i=1}^{4} k^{i}=1 \text {. }
$$


Table 1

Regression data to calculate performance indicators for each component of the balanced scorecard

\begin{tabular}{|c|c|}
\hline Performance indicator & Linear regression model equation \\
\hline \multicolumn{2}{|r|}{ Financial component } \\
\hline Integral liquidity indicator & $\begin{array}{l}I_{l}^{i}(t)=7.16201+0.64093 \times \mathrm{x}_{1}^{1}-0.57285 \times \mathrm{x}_{1}^{2}+0.17591 \times \mathrm{x}_{1}^{3}-2.80777 \times \mathrm{x}_{1}^{4}+0.07226 \times \mathrm{x}_{1}^{5} \\
\left(\mathrm{x}_{1}^{1} \ldots \mathrm{x}_{1}^{5}-\text { key liquidity indicators }\right)\end{array}$ \\
\hline $\begin{array}{l}\text { Integral indicator of activity } \\
\text { efficiency (profitability) }\end{array}$ & $\begin{array}{l}I_{r}^{i}(t)=46.154668+33.559512 \times \mathrm{x}_{\mathrm{r}}^{1}+10,646328 \times \mathrm{x}_{\mathrm{r}}^{2}+10,433401 \times \mathrm{x}_{\mathrm{r}}^{3}+ \\
4,240264 \times \mathrm{x}_{\mathrm{r}}^{4}-8,460438 \times \mathrm{x}_{\mathrm{r}}^{5}+0,920808 \times \mathrm{x}_{\mathrm{r}}^{6}-29,461838 \times \mathrm{x}_{\mathrm{r}}^{7}\left(\mathrm{x}_{\mathrm{r}}^{1} \ldots \mathrm{x}_{\mathrm{r}}^{7}-\text { key indicators of activity efficiency }\right. \\
(\text { profitability }))\end{array}$ \\
\hline $\begin{array}{l}\text { Integral indicator } \\
\text { of financial stability } \\
\text { (independence) }\end{array}$ & $\begin{array}{l}I_{f s}^{i}(t)=0,4070851+0,0194922 \times \mathrm{x}_{\mathrm{fs}}^{1}+0.013377 \times \mathrm{X}_{\mathrm{fs}}^{2}-0.0875679 \times \mathrm{X}_{\mathrm{fs}}^{3}++0.1029323 \times \mathrm{X}_{\mathrm{fs}}^{4}-0.0218667 \times \mathrm{X}_{\mathrm{fs}}^{5}+ \\
0.0040895 \times \mathrm{X}_{\mathrm{fs}}^{6}+0.0101263 \times \mathrm{X}_{\mathrm{fs}}^{7}-0.0115091 \times \mathrm{X}_{\mathrm{fs}}^{8}\left(\mathrm{X}_{\mathrm{fs}}{ }^{1} \ldots \mathrm{x}_{\mathrm{fs}}^{8} \text { are key indicators of financial stability }\right. \\
\text { (independence) }\end{array}$ \\
\hline $\begin{array}{l}\text { Integral indicator } \\
\text { of business activity }\end{array}$ & $\begin{array}{l}I_{b . a .}^{i}(t)=0.4797345+0.0006811 \times \mathrm{x}_{\text {b.a. }}{ }^{1}+0.0413736 \times \mathrm{x}_{\text {b.a. }}{ }^{2}-0.0053645 \times \mathrm{x}_{\text {d. a. }}{ }^{3}-0.0027783 \times \mathrm{x}_{\text {b.a. }}{ }^{4}+0.0022412 \times \mathrm{x}_{\text {b.a. }}{ }^{5} \\
\left(\mathrm{x}_{\text {b.a. }}{ }^{5} \cdots \mathrm{x}_{\text {b.a. }}{ }^{5} \text { are key indicators of business activity) }\right.\end{array}$ \\
\hline $\begin{array}{l}\text { Integral indicator } \\
\text { of property status }\end{array}$ & 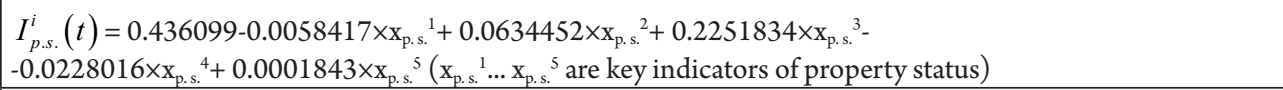 \\
\hline $\begin{array}{l}\text { Performance indicator } \\
\text { of financial component }\end{array}$ & Expert assessment of the impact of financial component Integral indicators \\
\hline \multicolumn{2}{|r|}{ Subscriber component } \\
\hline $\begin{array}{l}\text { Performance indicator } \\
\text { of subscriber component }\end{array}$ & $\begin{array}{l}K_{\text {sub }}^{i}(t)=-0.07106-0.07431 \times \mathrm{x}_{\text {sub }}{ }^{1}+18.46858 \times \mathrm{x}_{\text {sub }}{ }^{2}-7.52569 \times \mathrm{x}_{\text {sub }}{ }^{3}++27.24122 \times \mathrm{x}_{\text {sub }}{ }^{4} \\
\left(\mathrm{x}_{\mathrm{ab}} \ldots \mathrm{x}_{\text {sub }}{ }^{4} \text { are key indicators to evaluate the subscriber component }\right)\end{array}$ \\
\hline \multicolumn{2}{|r|}{ Domestic business process component } \\
\hline $\begin{array}{l}\text { Performance indicator } \\
\text { of domestic business } \\
\text { process component }\end{array}$ & $\begin{array}{l}I_{b p}(t)=0.145922+0.049686 \times \mathrm{x}_{\mathrm{bp}}{ }^{1}+0.075852 \times \mathrm{x}_{\mathrm{bp}}{ }^{2}+0.36897 \times \mathrm{x}_{\mathrm{bp}}{ }^{3}+0.043512 \times \mathrm{x}_{\mathrm{bp}}{ }^{4} \\
\left(\mathrm{x}_{\mathrm{bp}} \ldots \mathrm{x}_{\mathrm{bp}}{ }^{4} \text { are key indicators of internal business processes }\right)\end{array}$ \\
\hline \multicolumn{2}{|r|}{ Personnel training and development component } \\
\hline $\begin{array}{l}\text { Performance indicator } \\
\text { of personnel training and } \\
\text { development component }\end{array}$ & $\begin{array}{l}I_{p t d}(t)=0.4362803+0.2019133 \times \mathrm{x}_{\mathrm{ptd}}{ }^{1}+0.0011965 \times \mathrm{x}_{\mathrm{ptd}}{ }^{2}-0.0012965 \times \mathrm{x}_{\mathrm{ptd}}{ }^{3}+0.0944455 \times \mathrm{x}_{\mathrm{ptd}}-0.1283662 \times \mathrm{x}_{\mathrm{ptd}}{ }^{5} \\
\left(\mathrm{x}_{\mathrm{ptd}} \cdots \cdots \mathrm{x}_{\mathrm{ptd}}{ }^{5} \text { are key assessment indicator components of personnel training and development }\right)\end{array}$ \\
\hline
\end{tabular}

Source: author's calculations

The degree of consistency by the experts is determined on the basis of calculating Kendall's coefficient of concordance (Birbirenko, Zhadanova \& Banket, 2021).

Normalization of individual indicators of each individual component of the balanced scorecard is reduced to the following:

$$
I_{i}=\frac{I_{i}(x)-I_{\text {min }}}{I_{\text {max }}-I_{\text {min }}},
$$

where $0 " I_{i}^{\prime \prime} 1$.

This procedure is designed to ensure comparability of characteristics that are part of the overall integral indicator of economic stability of a telecommunications company. The normalized indicators must comply with zero dimension, a single variation interval.

The value of economic stability and its level increases if the overall integral indicator (IOES) is up to one. The interpretation of the indicator can be obtained using Harrington's Frustration Discomfort Scale (Lahutin, 2007), a meaningful description of which is given in Table 2 .
The scientific and methodological approach to integrally assess economic stability with positioning depending on the stage of business development of the telecommunications company is shown in Figure 1.

Therefore, ensuring the economic stability of the telecommunications company is formed on the basis of its assessment at each level and a separate component of the balanced scorecard assessment indicators, based on the analysis of factors influencing the economic environment of the communications service provider, on the study of patterns of formation and effectiveness of strategic management mechanisms.

The results of a comprehensive assessment of the economic stability of the telecommunications companies that were analyzed are shown in Table 3.

All three telecommunications companies that were analyzed are developing sustainably. However, the indicators of their level of economic stability differ. During the entire reporting period (2016-2020), Ukrtelecom PJSC was characterized to have a lower level of economic stability than other communications 
Vol. 7 No. 3, 2021

Table 2

Interpretation of overall integral indicator of economic stability of a company according to Harrington's Frustration Discomfort Scale

\begin{tabular}{|c|c|l|}
\hline Assessment intervals & Qualitative level & \multicolumn{1}{c|}{ Assessment description } \\
\hline $0 \ldots 0.2$ & Lory Bad) & $\begin{array}{l}\text { Destabilization of all business processes of a company, which promotes a catastrophically } \\
\text { low level of economic stability. }\end{array}$ \\
\hline $0.2 \ldots 0.37$ & Average (Satisfactory) & $\begin{array}{l}\text { Significant decrease in business efficiency, decline of one or more business processes, which } \\
\text { decreases the level of economic stability. }\end{array}$ \\
\hline $0.37 \ldots 0.63$ & High (Good) & $\begin{array}{l}\text { Functioning of a company is characterized by good performance indicators and a sufficient } \\
\text { the limit, and the economic situation is unstable. } \\
\text { level of economic stability. }\end{array}$ \\
\hline $0.63 \ldots 0.8$ & Very High (Excellent) & $\begin{array}{l}\text { The absolute level of economic stability which is not affected by any destabilizing influence } \\
\text { retains and increases its importance. }\end{array}$ \\
\hline $0.8 \ldots 1$ &
\end{tabular}

Source: drafted by the author, based on individual information processing (Lahutin, 2007)

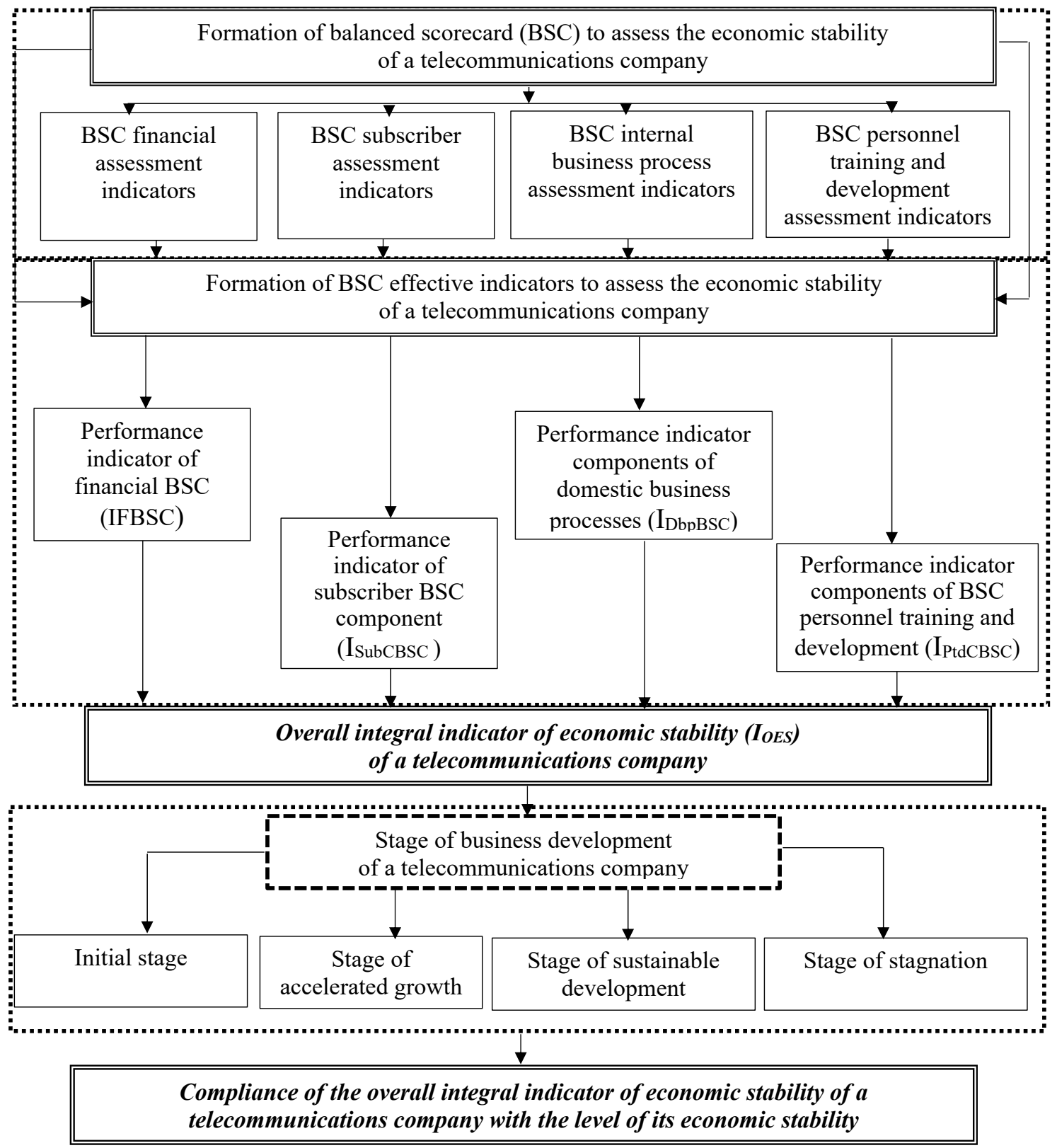

Figure 1. Scientific and methodological approach to assess economic stability of the telecommunications company comprehensively Source: author's solution 
Table 3

General integral indicator of economic stability of the telecommunications companies $\left(I_{O E S}\right)$ 2016-2020

\begin{tabular}{|l|c|c|c|c|c|}
\hline Name of telecommunications company & 2016 & 2017 & 2018 & 2019 & 2020 \\
\hline Ukrtelecom PJSC & 0.77717 & 0.65921 & 0.60649 & 0.62914 & 0.63382 \\
\hline Kyivstar PJSC & 0.89114 & 0.82656 & 0.88533 & 0.87197 & 0.84815 \\
\hline VF Ukraine PJSC & 0.88224 & 0.83516 & 0.81577 & 0.85214 & 0.83866 \\
\hline
\end{tabular}

Source: author's calculations

service providers, whereas Kyivstar PJSC has the highest. According to Harrington's Frustration Discomfort Scale, Kyivstar PJSC and VF Ukraine PrJSC have a high level of economic stability, while Ukrtelecom PJSC has an average level.

Kyivstar PJSC was launched in 1997. The provider has more than 25 million of subscribers, and the coverage area includes the largest cities and more than 10,000 towns across the country, offering $3 \mathrm{G}, 4 \mathrm{G}$ and LTE.

VF Ukraine PrJSC was previously owned by MTS, but in 2019, it moved to NEQSOL Holding, after which it was rebranded. The customer database is 19.8 million subscribers. The provider offers extensive network coverage $-86 \%$ of $3 \mathrm{G}$ coverage in all territories and $66 \%$ of $4 \mathrm{G}$ coverage. The company is also actively deploying networks for web-enabled NB-IoT.

Kyivstar PJSC and VF Ukraine PrJSC are major players in the mobile communications market, while Ukrtelecom PJSC is the leader of the fixedline telephony network in Ukraine. However, in 2020, Ukrtelecom PJSC received 2.087 billion UAH from fixed Internet subscribers, which is $7 \%$ more than in 2019. This growth was facilitated by the modernization of infrastructure and the construction of an optical network. Meanwhile, in 2020, Kyivstar PJSC advanced Ukrtelecom PJSC in terms of the number of users (up to 1.1 million subscribers) and became the market leader in fixed broadband access.

\section{Conclusions}

The functioning of modern telecommunications companies is conditioned by the crisis caused by the spread of COVID-19, which definitely has a negative impact on the economic stability of communications service providers in general and their business processes in particular. These impacts are diverse and directly depend on the stage of business development of the company. Therefore these crisis conditions show the level of economic stability of a telecommunications company, it is proposed to use the developed scientific and methodological approach to comprehensively assess economic stability with consistent justification of indicators, taking into account their positioning (significance) at a certain stage of business development: initial, accelerated growth, sustainable development or stagnation. The practical significance of the obtained research results lies in the formation of a scientific and methodologicalapproach to assess the economicstability of a company, taking into account its industry features (in particular, the features of the telecommunications sector), which provides certain advantages in the development of anti-crisis measures and programs. The development of theoretical and methodological approaches, methodological foundations and practical recommendations for strategic management of the economic stability of the telecommunications company are the prospects for further scientific study.

\section{References:}

Afonichkin, A. I., \& Zhurova, L. I. (2015). Model for assessing the economic sustainability of enterprises. Basic research, 10(1), 131-136.

Revenko, D. S., \& Dyba, V. A. (2014). Integral models of economic sustainability of an enterprise and tools for its visualization. Bulletin of the Eastern European University of Economics and Management, 1(16), 148-159.

Brahinets, A. M. (2009). Economic stability of enterprises in modern economic conditions. Scientific Bulletin of Luhansk National Agrarian University, 5, 49-57.

Ulianchenko, O. V. (2006). Formation and use of resource potential in the agricultural sector. Monograph, $357 \mathrm{p}$.

Tridid, O. M. (2002). Comprehensive assessment of the competitive status of the enterprise. Developmenteconomics, 2, 75-76.

Siegrist, M., Bowman, G., Mervine, E., \& Southam, C. (2019). Embedding environment and sustainability into corporate financial decision-making. Accounting \& Finance, 60 (1), 129-147. DOI: https://doi.org/10.1111/ acfi. 12533

Fetzer, T., Hensel, L., Hermle, J., \& Roth, C. (2020). Coronavirus perceptions and economic anxiety. Review of Economics and Statistics, 1(36). DOI: https://doi.org/10.1162/rest_a_00946

Gern, Klaus-Jürgen, Mösle, Saskia (2020). The impact of the COVID-19 pandemic on the global economy: Surveybased evidence from free zones. Kiel Policy Brief, 139, Kiel Institute for the World Economy (IfW), Kiel. 
Carlsson-Szlezak, P., Martin Reeves, M., \& Swartz, P. (2020). What Coronavirus Could Mean for the Global Economy. Harvard Business Review, March 03, 2020. Available at: https://hbr.org/2020/03/what-coronaviruscould-mean-for-the-global-economy

Burlaka, O. M. (2014). Ensuring sustainable development of the agricultural sector of the region on the basis of indicative planning. Agrosvit, 7, 51-56.

Hordiienko, M. I. (2011). Economic stability of the enterprise and risk factors. Business navigator, 4, 5-10.

Kobets, S. P. (2015). Methodical approach to assessing the economic stability of the enterprise. Global and national economic problems, 3, 37-44.

Yurchenko, A. Y. (2018). Formation and increase of the level of economic stability of flour-milling enterprises. PhD Thesis, Kherson, 283 p.

Kravchenko, M. O. (2016). Methodological bases of the system analysis of economic stability of the industrial enterprises. Technological audit and production reserves, 1/3(27), 84-89.

Voronkova, A. E. (2007). Diagnosis of the state of the enterprise: theory and practice. Monograph, 520 p.

Ishchenko, S. V. (2011). Improving the system of diagnostics of the level of viability of an industrial enterprise. Efficient economy, 6. Available at: http://www.economy.nayka.com.ua

Otchenashenko, O. A. (2011). Methodical approaches to assessing the economic stability of the enterprise. Bulletin of ZhSTU, 4(58), 89-92.

18. Birbirenko, S. S., Zhadanova, Yu. O., \& Banket, N. V. (2020). Influence of pandemic of coronavirus infection COVID-19 on economic resilience of Ukrainian enterprises. Economic Annals-XXI, 183 (5-6): 66-78. DOI: https://doi.org/10.21003/ea.V183-07

Lahutin, M. B. (2007). Visual mathematical statistics. Moscow, 472 p. 